\title{
Attention-Deficit/Hyperactivity Disorder Symptom Characteristics in Korean Elementary School Children: Comparison with US Population
}

\author{
Hyun Woo Choi ${ }^{1,2}$, Chi-Hyun Choi ${ }^{3}$, Myung Ho Lim ${ }^{2,4}$, Ho-Jang Kwon ${ }^{2,5}$, \\ Seung-Jin $\mathrm{Yoo}^{2}$, Ki Chung Paik ${ }^{2,6}$, and Kyoung Min Kim ${ }^{2,6} \bowtie$ \\ ${ }^{1}$ Department of Psychiatry, Dankook University Hospital, Cheonan, Republic of Korea \\ ${ }^{2}$ Environmental Health Center, Dankook University Medical Center, Cheonan, Republic of Korea \\ ${ }^{3}$ Division of Child and Adolescent Psychiatry, Department of Psychiatry, Seoul National University Hospital, Seoul, Republic of Korea \\ ${ }^{4}$ Department of Psychology, College of Public Human Resources, Dankook University, Cheonan, Republic of Korea \\ ${ }^{5}$ Department of Preventive Medicine, Dankook University College of Medicine, Cheonan, Republic of Korea \\ ${ }^{6}$ Department of Psychiatry, Dankook University College of Medicine, Cheonan, Republic of Korea
}

Objective Attention-deficit/hyperactivity disorder (ADHD) is a common neurodevelopmental disorder in elementary school children. The present study investigated the characteristics of ADHD in Korean elementary school children using the Korean version of the ADHD Rating Scale (K-ARS). The data was compared with those obtained from a comparable American population.

Methods Participants included 29,914 elementary school children, aged 6-12 years, from a medium-sized city. The parents completed the home version of the K-ARS. The total and subscale-specific normative data and sex- and age-related mean score differences were analyzed. These data were compared with those obtained from the American population using independent t-tests.

Results Mean total and subscale K-ARS scores were significantly higher among boys (vs. girls) and younger children aged equal to or less than 8 years old (vs. older children). Mean scores on the hyperactivity-impulsivity subscale were lower than those of American children, but similar to another Korean sample.

Conclusion Our data characterized ADHD symptoms in Korean children. However, further studies are needed to identify the cultural differences underlying ratings of $\mathrm{ADHD}$ symptom severity.

Psychiatry Investig 2019;16(6):425-432

Key Words ADHD, Impulsivity, Cross-cultural comparison, Child psychiatry.

\section{INTRODUCTION}

Attention-deficit/hyperactivity disorder (ADHD) is a neurodevelopmental disorder characterized by hyperactivity, impulsivity, and inattention. ${ }^{1}$ The worldwide prevalence of ADHD is estimated to be approximately $5 \%,{ }^{1,2}$ with a male sex bias estimated to be between 2:1 and 3:1.,3 ADHD is usually diagnosed at school age and symptomatically improves as children grow ${ }^{4,5}$; notably, hyperactivity and impul-

Received: November 28, 2018 Revised: January 23, 2019

Accepted: March 26, 2019

$\triangle$ Correspondence: Kyoung Min Kim, MD

Department of Psychiatry, Dankook University College of Medicine, 201 Manghyang-ro, Dongnam-gu, Cheonan 31116, Republic of Korea

Tel: +82-41-550-6390, Fax: +82-41-550-6968, E-mail: profuture@naver.com

(c) This is an Open Access article distributed under the terms of the Creative Commons Attribution Non-Commercial License (https://creativecommons.org/licenses/by$\mathrm{nc} / 4.0$ ) which permits unrestricted non-commercial use, distribution, and reproduction in any medium, provided the original work is properly cited. sivity improve earlier than does inattention, which might drive the change in the prevalence of diagnostic subtypes of ADHD observed with aging. ${ }^{6.7}$ However, recent studies have reported that symptoms in approximately half of the patients diagnosed with childhood ADHD persist into adulthood and cause some degree of functional impairment. ${ }^{8-10}$

The ADHD Rating Scale (ARS) is a norm-referenced checklist that was developed to assess the severity of ADHD symptoms. It was originally developed with 14 items based on the diagnostic criteria of the Diagnostic and Statistical Manual of Mental Disorders, Third Edition (DSM-III), and was revised to include 18 items in the DSM-IV. ${ }^{11,12}$ The ARS has been validated in multiple studies and translated and validated in a number of countries, including Iceland and Denmark. ${ }^{13-15}$ The Korean version of the ARS (K-ARS) was validated by So et al. ${ }^{16}$ and has been used in multiple studies with Korean children. ${ }^{17,18}$ 
Normative data of K-ARS scores among Korean elementary school children have been previously reported, ${ }^{19,20}$ but these studies were limited by small sample sizes. With a large enough sample size, collecting normative data from a population provides important indications of symptom distribution in the general population and allows for culture-specific optimization of screening thresholds. Hypothetically, the score distribution of a scale such as the K-ARS may differ from one country to another because of cultural differences that might alter the expression of symptoms. The present study thus aimed to determine the normative data of K-ARS scores in a large population of Korean school-age children. Furthermore, we compared these data to those from previous Korean studies, as well as to those obtained in the United States to explore the expression of ADHD symptoms possibly unique to Korean populations.

\section{METHODS}

\section{Participants}

The participants were elementary school children aged 6-12 years who had participated in an ADHD screening program in Cheonan (population of about 600,000 as of 2008), and whose parents were required to complete the home version of the K-ARS. Of a target population of 49,573 children from 65 elementary schools, the parents of 30,552 children from 49 schools completed the screening questionnaire; a final sample of 29,914 was included after excluding those lacking data on age, sex, or K-ARS.

\section{Measurement}

Demographic variables including sex, age, parental education, and household income were measured. For the assessment of ADHD symptom severity, we used the K-ARS, an 18-item inventory in which severity is rated on 4-point Likert scales ( 0 to 3 points for each item; total score, $0-54$ ) using never or rarely, sometimes, often, or very often as responses. ${ }^{21}$ The K-ARS consists of two subscales, hyperactivity-impulsivity and inattention, represented by the scores from nine odd-numbered and nine even-numbered items, respectively. The Cronbach's a value for the total score, hyperactivity-impulsivity, and inattention subscales were $0.908,0.866$, and 0.820 , respectively.

\section{Statistical analysis}

Demographic variables and normative data were analyzed using frequency analysis and descriptive statistics. The scores representing normative data were provided for four cut-off points (the 80th, 90th, 93rd, and 98th percentiles). ${ }^{21}$ The differences between sex and age groups were analyzed using one-way analysis of variance (ANOVA) and Tukey's posthoc tests. The comparison between these data and those of the US population ${ }^{21}$ was performed using independent $\mathrm{t}$ tests. Statistical analyses were conducted using the software package SPSS 18.0 for windows.

\section{Ethics statement}

The study protocol was approved by the Institutional Review Board for Human Subjects of a University Hospital in Cheonan, South Korea (IRB 0801-006). All participants and their parents were provided with information on the study and signed informed consent forms before enrolment.

Table 1. Demographic characteristics of participants

\begin{tabular}{|c|c|}
\hline & $\mathrm{N}(\%)^{*}$ \\
\hline \multicolumn{2}{|l|}{ Sex } \\
\hline Male & $14,933(49.9)$ \\
\hline Female & $14,981(50.1)$ \\
\hline \multicolumn{2}{|l|}{ Age (years) } \\
\hline 6 & $516(1.7)$ \\
\hline 7 & $6,388(21.4)$ \\
\hline 8 & $4,970(16.6)$ \\
\hline 9 & $4,943(16.5)$ \\
\hline 10 & $4,836(16.2)$ \\
\hline 11 & $4,571(15.3)$ \\
\hline 12 & $3,690(12.3)$ \\
\hline \multicolumn{2}{|l|}{ Parental education } \\
\hline \multicolumn{2}{|l|}{ Father } \\
\hline$<12$ years & $611(2.1)$ \\
\hline 12 years & $11,152(38.4)$ \\
\hline$>12$ years & $17,256(59.5)$ \\
\hline Unknown & $895(3.0)$ \\
\hline \multicolumn{2}{|l|}{ Mother } \\
\hline$<12$ years & $621(2.1)$ \\
\hline 12 years & $15,706(54.3)$ \\
\hline$>12$ years & $12,623(43.6)$ \\
\hline Unknown & $964(3.2)$ \\
\hline \multicolumn{2}{|c|}{ Household income } \\
\hline$<1,000$ & $516(3.2)$ \\
\hline $1,000-2,000$ & $2,179(13.4)$ \\
\hline $2,000-3,000$ & $5,092(31.3)$ \\
\hline $3,000-4,000$ & $4,194(25.8)$ \\
\hline $4,000-5,000$ & $2,239(13.8)$ \\
\hline$>5,000$ & $2,048(12.6)$ \\
\hline Unknown & $13,646(45.6)$ \\
\hline
\end{tabular}

* percentages were calculated after excluding missing information. Percentages presented within parentheses are for missing information among total subjects 


\section{RESULTS}

\section{Demographic variables}

Detailed demographic information is presented in Table 1. Of the total sample of 29,914 children, $49.9 \%$ were boys. The proportions of the total population comprised by each age group is presented in Table 1; it should be noted that 6-yearold children accounted for only $1.7 \%$ because most first grade children were 7 years old. Among the participants, 29,019, 28,950 , and 16,268 responded to the paternal and maternal educational level and household income, respectively. The most common response regarding paternal educational level was "more than 12 years," while that concerning maternal educational level was "equal to 12 years." There were significant main effects of paternal educational levels $(\mathrm{F}=203.56$, $\mathrm{p}<0.001)$ and maternal educational levels $(\mathrm{F}=124.79, \mathrm{p}<0.001)$ on mean K-ARS scores of children. Post-hoc analyses revealed that a lower K-ARS score was associated with a higher educational level of parents. Household income was most frequently reported to be " 2 to 3 million Korean Won per month," followed by " 3 to 4 million Korean Won per month." Higher household income was significantly associated with lower K-ARS scores $(\mathrm{F}=32.497, \mathrm{p}<0.001)$.

\section{Differences in K-ARS scores according to sex and age groups}

The total scores and both subscale scores were significantly higher among boys than girls (Table 2). The total and subscale scores also differed significantly between age groups re- gardless of sex (Table 3). All scores were highest among 6 -year-old boys, followed by 8 -year-old boys; while total and hyperactivityimpulsivity subscale scores were lowest among 12 -year-old boys. The hyperactivityimpulsivity subscale scores among girls were highest in the 6-year-old group, followed by the 8 -year-old group. The total K-ARS and inattention subscale scores for girls were highest among 8-year-olds group and lowest in the 12-year-old group.

\section{Normative data and the distribution of K-ARS scores}

The total and subscale scores for each percentile cut-off (see section statistical analysis) by sex are presented in Table 4. The distributions of K-ARS total scores for each sex are shown in Figure 1.

\section{Comparison with US-population data}

Table 5 shows the comparisons between the data from this study and those from a US population that used the original version of the ARS. Because the present study did not include participants aged 5 or 13 years, the two studies only overlapped in their consideration of children aged 8-10 years; thus, comparisons were limited to data from this age range. There were no significant differences between populations in the inattention subscale for either sex. In contrast, both sexes in the US population had significantly higher hyperactivity-impulsivity subscale scores than those in our study. In addition, total ARS scores for the boys in the US population were significantly higher than those in our study. Finally, the total score cut-off values for the $80^{\text {th }}, 90^{\text {th }}, 93^{\text {rd }}$, and

Table 2. Mean K-ARS scores for boys and girls

\begin{tabular}{lcccc}
\hline & Boys $(\mathrm{N}=14,933)$ & Girls $(\mathrm{N}=14,981)$ & $\mathrm{t}$ & $\mathrm{p}$ \\
\hline Total score & $9.61(7.60)$ & $6.71(6.19)$ & 36.210 & $<0.001$ \\
Hyperactivity-impulsivity & $3.78(3.73)$ & $2.55(2.93)$ & 31.843 & $<0.001$ \\
Inattention & $5.84(4.40)$ & $4.17(3.71)$ & 35.490 & $<0.001$ \\
\hline
\end{tabular}

Table 3. Mean K-ARS scores by age group

\begin{tabular}{ccccccccccc}
\hline Age & 6 & 7 & 8 & 9 & 10 & 11 & 12 & $\mathrm{~F}$ & $\mathrm{p}$ & Post-hoc \\
\hline Boys (N) & 245 & 3,200 & 2,494 & 2,462 & 2,441 & 2,280 & 1,811 & & & \\
$\quad$ Total score & $10.48(8.19)$ & $9.44(7.37)$ & $10.07(7.76)$ & $9.77(7.81)$ & $9.34(7.39)$ & $9.74(7.73)$ & $9.19(7.45)$ & 4.033 & $<0.001$ & $8>7,10,12^{*}$ \\
Hyperactivity- & $4.31(4.08)$ & $3.85(3.73)$ & $4.05(3.91)$ & $3.82(3.85)$ & $3.60(3.61)$ & $3.73(3.64)$ & $3.48(3.52)$ & 6.108 & $<0.001$ & $6,7,8,9>12^{*}$ \\
$\quad$ Impulsivity & & & & & & & & & & \\
Inattention & $6.18(4.57)$ & $5.59(4.17)$ & $6.02(4.43)$ & $5.97(4.50)$ & $5.75(4.29)$ & $6.01(4.60)$ & $5.71(4.44)$ & 4.030 & $<0.001$ & $8,9,11>7^{*}$ \\
Girls (N) & 271 & 3,188 & 2,476 & 2,481 & 2,395 & 2,291 & 1,879 & & & \\
Total score & $6.92(5.88)$ & $6.82(6.03)$ & $7.15(6.32)$ & $6.75(6.38)$ & $6.64(6.30)$ & $6.41(6.02)$ & $6.34(6.08)$ & 4.408 & $<0.001$ & $8>11,12^{*}$ \\
Hyperactivity- & $2.76(2.93)$ & $2.66(2.95)$ & $2.73(3.02)$ & $2.53(3.03)$ & $2.51(2.93)$ & $2.39(2.74)$ & $2.36(2.85)$ & 5.220 & $<0.001$ & $7,8>11.12^{*}$ \\
Impulsivity & & & & & & & & & & \\
Inattention & $4.15(3.43)$ & $4.16(3.55)$ & $4.42(3.76)$ & $4.23(3.79)$ & $4.14(3.82)$ & $4.02(3.71)$ & $3.99(3.7)$ & 3.356 & 0.003 & $8>11,12^{*}$ \\
\hline
\end{tabular}

${ }^{*} \mathrm{p}<0.05$. K-ARS: Korean version of the attention-deficit/hyperactivity disorder Rating Scale 
$98^{\text {th }}$ percentiles in the $8-10$-year-old population considered by this study were 16.0, 20.0, 23.0, 31.0; while those in the 8-10-year-old US population were 20.0, 25.0, 27.0, and 42.2. ${ }^{21}$

\section{DISCUSSION}

The present study investigated the normative data collect-

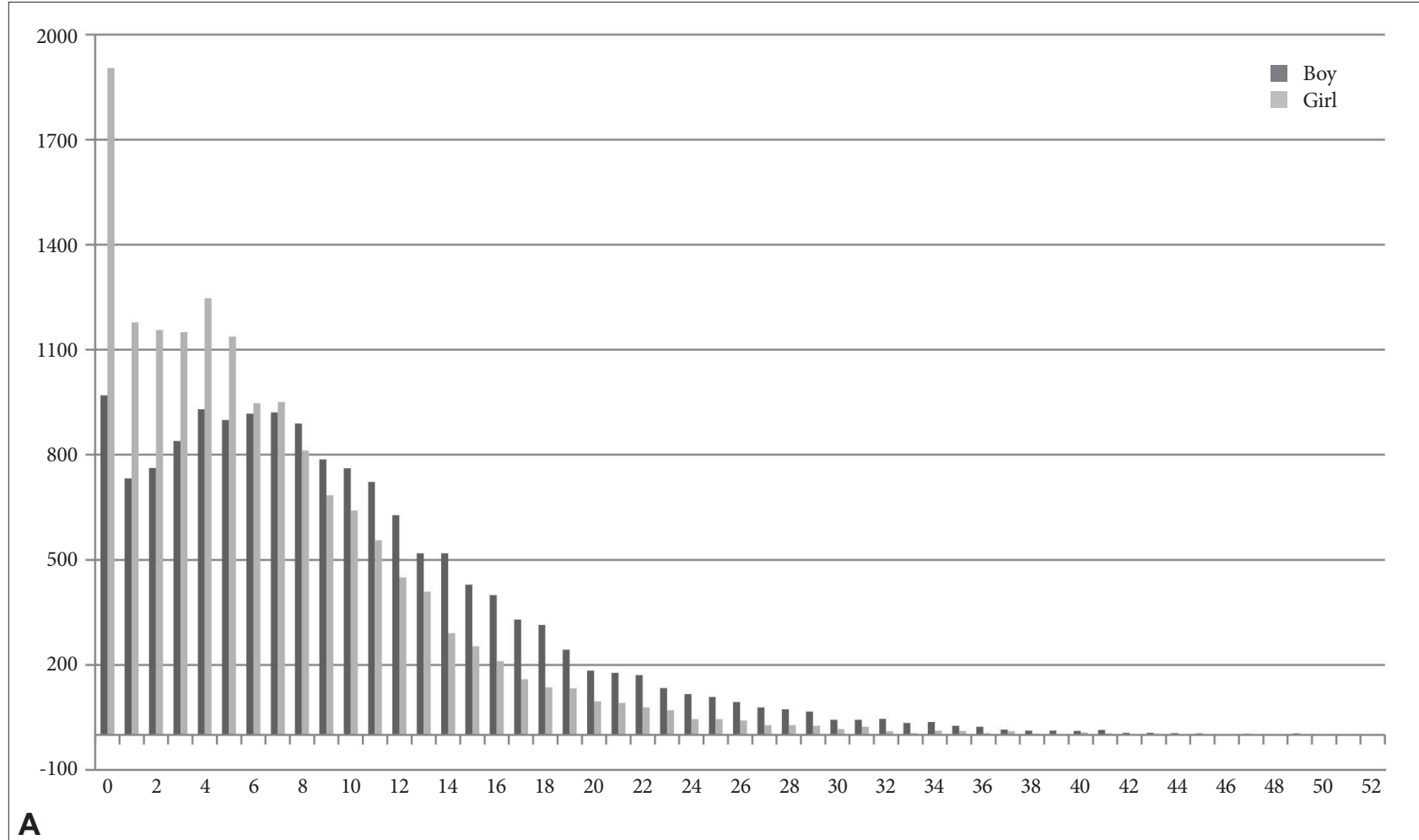

A

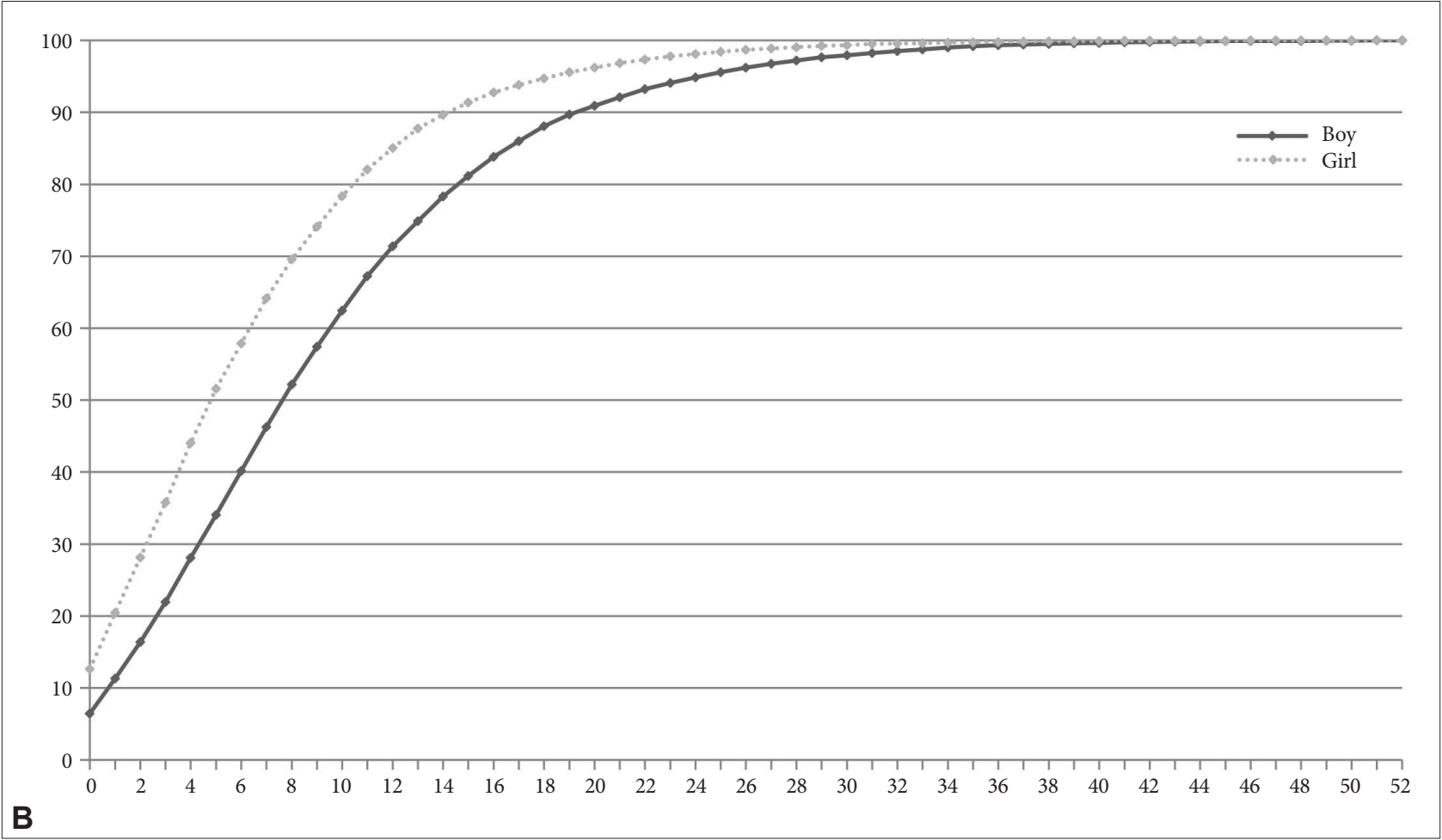

Figure 1. Distributions of participant frequency for each K-ARS score. A: Frequency according to each total K-ARS score. B: Curves demonstrating the percentiles for cumulative frequency of each total K-ARS score. 
ed using the K-ARS in a large community-based sample of elementary school children aged 6 to 12 years. Total K-ARS scores and scores on both subscales were significantly higher in boys than in girls, which is consistent with previous studies of normative ARS data from Korean and American general populations. ${ }^{20,21}$ In the analysis of K-ARS scores by age group, the scores of 8-year-olds were both the highest of all age groups and significantly higher than the lowest scores (those of the 12-year-olds) in both sexes. Although K-ARS scores slightly declined with age, it the trend was marginal. This finding is inconsistent with reports documenting a significant decline in ADHD symptom severity with age. ${ }^{22}$ However, it should be noted that these data were collected from the general population in which most children do not have ADHD. In fact, the findings of a previous study on normative data of the K-ARS were consistent with those of our study. ${ }^{19}$ Jang et al. ${ }^{19}$ also reported a slight decline in K-ARS scores from a peak at 8 years of age among Korean elementa-

Table 4. Normative data based on the suggested percentile cut-off points for the K-ARS by sex and age group

\begin{tabular}{|c|c|c|c|c|c|c|c|c|c|c|c|c|}
\hline \multirow{2}{*}{$\begin{array}{c}\text { Age } \\
\text { (years) }\end{array}$} & \multicolumn{4}{|c|}{ Total score } & \multicolumn{4}{|c|}{ Hyperactivity-impulsivity } & \multicolumn{4}{|c|}{ Inattention } \\
\hline & $80^{\text {th }} \%$ ile & $90^{\text {th }} \%$ ile & $93^{\text {th }} \%$ ile & $98^{\text {th }} \%$ ile & $80^{\text {th }} \%$ ile & $90^{\text {th }} \%$ ile & $93^{\text {th }} \%$ ile & $98^{\text {th }} \%$ ile & $80^{\text {th }} \%$ ile & $90^{\text {th }} \%$ ile & $93^{\text {th }} \%$ ile & $98^{\text {th }} \%$ ile \\
\hline \multicolumn{13}{|l|}{ Boys } \\
\hline 6 & 17 & 23 & 26 & 31 & 7 & 11 & 12 & 15 & 9 & 13 & 14 & 18 \\
\hline 7 & 15 & 19 & 22 & 30 & 6 & 9 & 10 & 15 & 9 & 11 & 12 & 17 \\
\hline 8 & 16 & 20 & 23 & 31 & 7 & 9 & 11 & 15 & 9 & 12 & 13 & 18 \\
\hline 9 & 15 & 20 & 22 & 31 & 6 & 9 & 10 & 15 & 9 & 12 & 13 & 18 \\
\hline 10 & 15 & 19 & 21 & 29 & 6 & 8 & 10 & 14 & 9 & 12 & 13 & 16 \\
\hline 11 & 16 & 20 & 23 & 31 & 6 & 9 & 10 & 14 & 9 & 12 & 14 & 18 \\
\hline 12 & 15 & 19 & 21 & 28 & 6 & 8 & 10 & 13 & 9 & 12 & 13 & 17 \\
\hline \multicolumn{13}{|l|}{ Girls } \\
\hline 6 & 11 & 14 & 16 & 23 & 5 & 7 & 7 & 11 & 7 & 9 & 9 & 13 \\
\hline 7 & 11 & 15 & 16 & 23 & 4 & 7 & 8 & 11 & 7 & 9 & 9 & 14 \\
\hline 8 & 11 & 15 & 17 & 25 & 4 & 7 & 8 & 12 & 7 & 9 & 10 & 15 \\
\hline 9 & 11 & 15 & 17 & 25 & 4 & 6 & 7 & 12 & 7 & 9 & 10 & 14 \\
\hline 10 & 11 & 15 & 17 & 24 & 4 & 6 & 8 & 11 & 7 & 9 & 10 & 15 \\
\hline 11 & 11 & 14 & 16 & 23 & 4 & 6 & 7 & 10 & 7 & 9 & 10 & 15 \\
\hline 12 & 11 & 14 & 16 & 23 & 7 & 9 & 10 & 14 & 7 & 9 & 10 & 14 \\
\hline
\end{tabular}

K-ARS: Korean version of the attention-deficit/hyperactivity disorder Rating Scale

Table 5. K-ARS mean scores for this population and a US population ${ }^{21)}$

\begin{tabular}{|c|c|c|c|c|c|c|}
\hline \multirow{2}{*}{$\begin{array}{c}\text { Age range } \\
\text { (years) }\end{array}$} & \multicolumn{2}{|c|}{ Present study $(\mathrm{N}=29,914)$} & \multicolumn{2}{|c|}{$\mathrm{US}^{21)}(\mathrm{N}=814)$} & \multicolumn{2}{|c|}{ Difference between studies } \\
\hline & Boys & Girls & Boys & Girls & Boys & Girls \\
\hline ADHD total & & & & & $\mathrm{t}$ & $\mathrm{t}$ \\
\hline 5 to 7 & $9.52(7.43)$ & $6.83(6.02)$ & $12.54(9.97)$ & $9.51(8.17)$ & & \\
\hline 8 to 10 & $9.73(7.66)$ & $6.85(6.34)$ & $12.18(15.51)$ & $7.56(7.51)$ & $2.673^{*}$ & 1.683 \\
\hline 11 to 13 & $9.49(7.61)$ & $6.38(6.05)$ & $11.50(11.32)$ & $7.49(7.84)$ & & \\
\hline \multicolumn{7}{|c|}{ Hyperactive-Impulsivity } \\
\hline 5 to 7 & $3.89(3.75)$ & $2.67(2.95)$ & $6.59(5.56)$ & $5.00(4.53)$ & & \\
\hline 8 to 10 & $3.83(3.79)$ & $2.59(3.00)$ & $5.53(8.05)$ & $3.39(3.79)$ & $3.575^{*}$ & $3.765^{*}$ \\
\hline 11 to 13 & $3.62(3.59)$ & $2.37(2.79)$ & $4.79(5.54)$ & $2.88(3.48)$ & & \\
\hline \multicolumn{7}{|l|}{ Inattention } \\
\hline 5 to 7 & $5.63(4.20)$ & $4.16(3.54)$ & $5.94(5.08)$ & $4.51(4.45)$ & & \\
\hline 8 to 10 & $5.91(4.41)$ & $4.26(3.79)$ & $6.65(8.49)$ & $4.17(4.36)$ & 1.473 & -0.367 \\
\hline 11 to 13 & $5.88(4.53)$ & $4.01(3.71)$ & $6.70(6.27)$ & $4.61(5.12)$ & & \\
\hline
\end{tabular}

${ }^{*} \mathrm{p}<0.01$. K-ARS: Korean version of the attention-deficit/hyperactivity disorder (ADHD) Rating Scale 
ry school children.

Neurobiological changes concomitant with aging may account for the declining severity of ADHD symptom after 8 years : 'concrete operational period,' formerly conceptualized by Piaget, ${ }^{23}$ begins at $7-8$ years of age. From this point onward, inhibitory control increasingly develops throughout the childhood and adolescent period. ${ }^{24-26}$ Imaging studies on brain structures also indicate that gray-matter formation follows a u-shaped trajectory, where the apex is at 8 years of age. ${ }^{27}$ These findings suggest that the development of this period is different from that of the preschool period, which is characterized by expansive mental growth and blossoming nature. $^{28}$

The mean total K-ARS scores among boys and girls ranged from 9.19 to 10.48 and 6.34 to 7.15 , respectively. This is consistent with other studies that have analyzed normative KARS data in Korean populations; one such study found scores for the same age group to range from 9.08 to 11.03 (boys) and 5.38 to 8.37 (girls). ${ }^{19}$ On the other hand, the investigation of the US population that used the original version of the ARS demonstrated some significant differences from our study. While the inattention subscale scores did not differ between the Korean and US populations for either sex, the hyperactivity-impulsivity subscale scores of both sexes and the total scores of boys were significantly higher in the US population than in our study. The scores for the same $\left(80^{\text {th }}, 90^{\text {th }}, 93^{\text {rd }}\right.$, and $\left.98^{\text {th }}\right)$ percentile cut-offs as those used by DuPaul et al. ${ }^{21}$ were also higher than those found in the present study. As aforementioned, the US population featured total score cut-offs of at least 3-4 points higher than those of the population considered by the present study; further, the $98^{\text {th }}$ percentile of the former scored 11 points higher than the latter. Notably, a previous study that compared ARS scores between Japanese and US populations ${ }^{29}$ reported that the two populations exhibited a similar difference: hyperactivityimpulsivity subscale scores among both sexes and all age groups were higher in the US population than the Japanese population.

There are some plausible explanations for these differences. DuPaul et al. ${ }^{21}$ reported scores differed according to ethnicity. The disparity in scores might reflect real behavioral differences between populations that can be affected by various genetic, environmental, or cultural factors. For instance, the prevalence of the dopamine D4 receptor 7-repeat allele, which is correlated with an increased expression of ADHD, is reported to be very low in Asian populations. ${ }^{30,31}$ In addition, differences in dietary habits or other daily routines might also influence the behavior of children. For example, Howard et al. ${ }^{32}$ reported an association between a Western dietary pattern and ADHD. Finally, behavior is also affected by cultural factors. Compared to Western cultures, Asian cultures are more collectivistic and emphasize group awareness over individual interest; this difference has been hypothesized to influence the expression of hyperactivity. ${ }^{29,33}$ Asian children are also reportedly more introverted than their American counterparts; such introversion could partially mask hyperactivity. ${ }^{29,34}$

The differences in parental recognition of ADHD and its symptoms could explain-at least in part-the score differences between the Korean and US populations. Parental recognition may be related to ethnicity and socioeconomic status. For example, Bussing et al. ${ }^{35}$ reported that Caucasian parents were more likely than African-American parents to apply medical labels, expect a lifelong course of treatment, and include school interventions in the overall treatment plan. Cultural differences may also affect the scoring style of parents; i.e., on Likert scales, raters from collectivistic cultures tend to moderate their scores (i.e., score middle values), while those from individualistic cultures are more likely to use extreme values. ${ }^{36}$

Interestingly, despite these cultural differences, the prevalence of ADHD did not differ significantly between cultures. The prevalence of the condition in Korean populations is reportedly between $5.90 \%$ to $6.50 \%$, similar to the worldwide prevalence. ${ }^{17,37,38}$ In a meta-analysis of the worldwide prevalence of ADHD, Polanczyk et al. ${ }^{2,39}$ also reported that geographic location plays a limited role in its large variability. Currently, there is no straightforward interpretation for these differences and similarities in ADHD symptom scores in the general population. Future cross-cultural studies will be required to identify the pathophysiology and ethnic differences underlying ADHD.

\section{Strengths and limitations}

The present study is subject to several limitations. First, our data were collected from only one medium-sized city in Korea, which limits generalizability of the results to the whole Korean population. However, the present findings are similar to the those of a study conducted in Seoul, a much larger city that can be considered more representative of the total population in Korea. Secondly, the participants were limited to elementary school children aged 6-12 years even though ADHD symptoms that cause functional impairment can persist into adolescence and adulthood; further studies are therefore needed to investigate the expression of ADHD symptoms in teenagers and adults. Thirdly, we only used parental reports; ADHD is diagnosed only when symptoms are observed in more than two situations, so a teacher's ratings can be as important as that of the parents. Finally, diagnostic interviews performed by qualified clinicians might enhance 
the quality of the evaluations of the children's symptoms.

\section{Conclusions}

This study provides data that advance our understanding of the similarities and differences in expression of ADHD across cultures and confirm the results of previous Korean studies with smaller sample sizes. Furthermore, our study will help clinicians to evaluate their patients using the K-ARS and determine therapeutic plan by referencing the normative data.

\section{Acknowledgments}

This study was financially supported by the Ministry of Environment, Republic of Korea.

\section{Conflicts of Interest}

The authors have no potential conflicts of interest to disclose.

\section{Author Contributions}

Conceptualization: MH Lim, HJ Kwon, KC Paik, KM Kim. Data curation: SJ Yoo, MH Lim, HJ Kwon, KC Paik. Formal analysis: HW Choi, CH Choi, KM Kim. Funding acquisition: MH Lim, HJ Kwon, KC Paik. Investigation: MH Lim, HJ Kwon. Methodology: HW Choi, MH Lim, HJ Kwon, KM Kim. Project administration: MH Lim, HJ Kwon, KC Paik, KM Kim. Resources: MH Lim, HJ Kwon, KC Paik. Software: MH Lim, HJ Kwon. Supervision: KM Kim, MH Lim. Validation: HJ Kwon, MH Lim, KM Kim. Visualization: HW Choi, CH Choi, KM Kim. Writing-original draft: HW Choi, KM Kim. Writing_review \& editing: HW Choi, CH Choi, KM Kim.

\section{ORCID iDs}

$\begin{array}{ll}\text { Kyoung Min Kim } & \text { http://orcid.org/0000-0003-0577-0701 } \\ \text { Hyun Woo Choi } & \text { http://orcid.org/0000-0002-1873-0453 } \\ \text { Chi-Hyun Choi } & \text { http://orcid.org/0000-0003-2120-1111 } \\ \text { Myung Ho Lim } & \text { http://orcid.org/0000-0001-5370-4376 } \\ \text { Hojang Kwon } & \text { http://orcid.org/0000-0003-3029-5674 } \\ \text { Seung-Jin Yoo } & \text { http://orcid.org/0000-0002-0643-5609 } \\ \text { Ki-Chung Paik } & \text { http://orcid.org/0000-0003-4210-8055 }\end{array}$

\section{REFERENCES}

1. American Psychiatric Association. Diagnostic and Statistical Manual of Mental Disorders, Fifth Edition (DSM-52®). Arlington, VA: American Psychiatric Association Publishing; 2013.

2. Polanczyk GV, de Lima MS, Horta BL, Biederman J, Rohde LA. The worldwide prevalence of ADHD: a systematic review and metaregression analysis. Am J Psychiatry 2007;164:942-948.

3. American Psychiatric Association Task Force on DSM-IV. Diagnostic and Statistical Manual of Mental Disorders: DSM-IV-TR. Washington, DC: American Psychiatric Association Publishing; 2000.

4. Faraone SV, Biederman J, Mick E. The age-dependent decline of attention deficit hyperactivity disorder: a meta-analysis of follow-up studies. Psychol Med 2006;36:159-165.

5. Kessler RC, Berglund P, Demler O, Jin R, Merikangas KR, Walters EE. Lifetime prevalence and age-of-onset distributions of DSM-IV disorders in the National Comorbidity Survey Replication. Arch Gen Psychiatry 2005;62:593-602.

6. Biederman J, Mick E, Faraone SV. Age-dependent decline of symptoms of attention deficit hyperactivity disorder: impact of remission definition and symptom type. Am J Psychiatry 2000;157:816-818.

7. Lahey BB, Pelham WE, Loney J, Lee SS, Willcutt E. Instability of the DSM-IV subtypes of ADHD from preschool through elementary school. Arch Gen Psychiatry 2005;62:896-902.

8. Biederman J, Petty CR, Evans M, Small J, Faraone SV. How persistent is ADHD? A controlled 10-year follow-up study of boys with ADHD. Psychiatry Res 2010;177:299-304.

9. Kessler RC, Green JG, Adler LA, Barkley RA, Chatterji S, Faraone SV, et al. Structure and diagnosis of adult attention-deficit/hyperactivity disorder: analysis of expanded symptom criteria from the Adult ADHD Clinical Diagnostic Scale. Arch Gen Psychiatry 2010;67:11681178.

10. Sobanski E, Brüggemann D, Alm B, Kern S, Deschner M, Schubert T, et al. Psychiatric comorbidity and functional impairment in a clinically referred sample of adults with attention-deficit/hyperactivity disorder (ADHD). Eur Arch Psychiatry Clin Neurosci 2007;257:371-377.

11. DuPaul GJ. Parent and teacher ratings of ADHD symptoms: psychometric properties in a community-based sample. J Clin Child Adolesc Psychol 1991;20:245-253.

12. Pappas D. ADHD Rating Scale-IV: Checklists, norms, and clinical interpretation. J Psychoeduc Assess 2006;24:172-178.

13. Döpfner M, Steinhausen HC, Coghill D, Dalsgaard S, Poole L, Ralston SJ, et al. Cross-cultural reliability and validity of ADHD assessed by the ADHD Rating Scale in a pan-European study. Eur Child Adolesc Psychiatry 2006;15:i46-i55.

14. Magnússon P, Smári J, Grétarsdóttir H, Prándardóttir H. Attentiondeficit/hyperactivity symptoms in Icelandic schoolchildren: assessment with the attention deficit/hyperactivity rating scale-IV. Scand J Psychol 1999;40:301-306.

15. Szomlaiski N, Dyrborg J, Rasmussen H, Schumann T, Koch S, Bilenberg N. Validity and clinical feasibility of the ADHD rating scale (ADHD-RS) A Danish Nationwide Multicenter Study. Acta Paediatr 2009;98:397-402.

16. So YK, Noh JS, Kim YS, Ko SG, Koh YJ. The Reliability and Validity of Korean Parent and Teacher ADHD Rating Scale. J Korean Neuropsychiatr Assoc 2002;41:283-289.

17. Cho SC, Hong YC, Kim JW, Park S, Park MH, Hur J, et al. Association between urine cotinine levels, continuous performance test variables, and attention deficit hyperactivity disorder and learning disability symptoms in school-aged children. Psychol Med 2013;43:209-219.

18. Yang SJ, Cheong S, Hong SD. Prevalence and correlates of attention deficit hyperactivity disorder: school-based mental health services in Seoul. J Korean Neuropsychiatr Assoc 2006;45:69-76.

19. Jang SJ, Suh DS, Byun HJ. Normative study of the K-ARS (Korean ADHD Rating Scale) for parents. J Kor Acad Child Adolesc Psychiatry 2007;18:38-48.

20. Kim YS, So YK, Noh JS, Choi NK, Kim SJ, Koh YJ. Normative Data on the Korean ADHD Rating Scales (K-ARS) for Parents and Teacher. J Korean Neuropsychiatr Assoc 2003;42:352-359.

21. DuPaul GJ, Anastopoulos AD, Power TJ, Reid R, Ikeda MJ, McGoey KE. Parent ratings of attention-deficit/hyperactivity disorder symptoms: factor structure and normative data. J Psychopathol Behav Assess 1998;20:83-102.

22. Spencer TJ, Biederman J, Mick E. Attention-deficit/hyperactivity disorder: diagnosis, lifespan, comorbidities, and neurobiology. J Pediatr Psychol 2007;32:631-642.

23. Piaget J. Piaget's Theory. In: Mussen PH, Editor. Carmichael's Handbook of Child Development. New York: Wiley, 1970, p.703-732.

24. Houdé O, Borst G. Evidence for an inhibitory-control theory of the reasoning brain. Front Hum Neurosci 2015;9:148.

25. Williams BR, Ponesse JS, Schachar RJ, Logan GD, Tannock R. Development of inhibitory control across the life span. Develop Psychol 1999;35:205-213.

26. Bedard AC, Nichols S, Barbosa JA, Schachar R, Logan GD, Tannock R. The development of selective inhibitory control across the life span. Develop Neuropsychol 2002;21:93-111.

27. Franke K, Luders E, May A, Wilke M, Gaser C. Brain maturation: predicting individual BrainAGE in children and adolescents using struc- 
tural MRI. Neuroimage 2012;63:1305-1312.

28. Brown TT, Jernigan TL. Brain development during the preschool years. Neuropsychol Rev 2012;22:313-333.

29. Tani I, Okada R, Ohnishi M, Nakajima S, Tsujii M. Japanese version of home form of the ADHD-RS: an evaluation of its reliability and validity. Res Dev Disabil 2010;31:1426-1433.

30. Leung PW, Lee C, Hung S, Ho T, Tang C, Kwong S, et al. Dopamine receptor D4 (DRD4) gene in Han Chinese children with attention-deficit/hyperactivity disorder (ADHD): increased prevalence of the 2-repeat allele. Am J Med Genet B Neuropsychiatr Genet 2005;133:54-56.

31. Luk, ES, Leung P, Ho TP. Cross-Cultural/Ethnic Aspects of Childhood Hyperactivity. In: Sandberg S, Editor. Hyperactivity and Attention Disorders of Childhood, Second Edition. Cambridge, UK: Cambridge University Press, 2002, p.79-81.

32. Howard AL, Robinson M, Smith GJ, Ambrosini GL, Piek JP, Oddy WH. ADHD is associated with a "Western" dietary pattern in adolescents. J Atten Disord 2011;15:403-411.

33. Schwartz D, Farver JM, Chang L, Lee-Shin Y. Victimization in South Korean children’s peer groups. J Abnorm Child Psychol 2002;30:113-125.
34. Chon A. Asia and America: how cultural differences create behavioral. Soc Impact Res Exp J 2014:1-14.

35. Bussing R, Schoenberg NE, Rogers KM, Zima BT, Angus S. Explanatory models of ADHD: do they differ by ethnicity, child gender, or treatment status? J Emot Behav Disord 1998;6:233-242.

36. Chiao JY. Cultural Neuroscience: Visualizing Culture-Gene Influences on Brain Function. In: Decety J, Cacioppo JT, Editors. Handbook of Social Neuroscience. UK: Oxford University Press; 2011.

37. Cho SC, Kim BN, Kim JW, Rohde LA, Hwang JW, Chungh DS, et al. Full syndrome and subthreshold attention-deficit/hyperactivity disorder in a Korean community sample: comorbidity and temperament findings. Eur Child Adolesc Psychiatry 2009;18:447-457.

38. Park S, Kim BN, Cho SC, Kim JW, Shin MS, Yoo HJ. Prevalence, correlates, and comorbidities of DSM-IV psychiatric disorders in children in Seoul, Korea. Asia Pac J Public Health 2015;27:NP1942-NP1951.

39. Polanczyk GV, Willcutt EG, Salum GA, Kieling C, Rohde LA. ADHD prevalence estimates across three decades: an updated systematic review and meta-regression analysis. Int J Epidemiol 2014;43:434-442. 